\title{
LÚDICO COMO FERRAMENTA PEDAGÓGICA NO PROCESSO ENSINO APRENDIZAGEM
}

\author{
Ramilis Moreira do Nascimento \\ Licenciado em Educação Física/ISECENSA/RJ \\ ramilis2006@gmail.com
}

Nilo Terra Arêas Neto

Mestre em Ciencia da Motricidade Humana/UCB/RJ

terra.nilo@gmail.com

\section{Emerson da Mota Saint'Clair}

Mestrado em Ciências da Atividade Física/UNIVERSO/RJ

emerson.saint@yahoo.com.br

\section{Mauricio Rocha Calomeni}

Mestre em Ciencia da Motricidade Humana/UCB/RJ

mauriciocalomeni@gmail.com

\section{RESUMO}

Objetivo do estudo foi verificar a influência do lúdico no desenvolvimento da aprendizagem e da praxia global de crianças matriculadas na educação infantil. A amostra foi composta por 40 indivíduos matriculados em 4 escolas da rede pública e privada, sendo 10 de cada escola. Para avaliação praxia global foram aplicados nas crianças os testes da bateria psicomotora de Vitor da Fonseca (1975) específicos para esse fator. Já para determinação da ludicidade das escolas e do nível de aprendizado das crianças foram utilizados questionários, respondidos pelos educadores, e adaptados da bateria psicomotora. Os dados foram tratados de forma descritiva e inferencial e os resultados mostraram homogeneidade entre as escolas no que diz respeito à ludicidade oferecida e o desenvolvimento da praxia global de suas crianças. Quanto à aprendizagem, na escola mais lúdica as crianças alcançaram melhores resultados, contudo tal assertiva não encontrou respaldo estatístico. Conclui-se que se faz necessário investigar um número maior de escolas a fim de se encontrar diferenças mais significativas no que diz respeito à ludicidade e dessa forma poder se registrar diferenças mais marcantes na praxia global e na aprendizagem.

Palavras-Chave: Educação Física Escolar, Ludicidade, Aprendizagem

\begin{abstract}
The objective of study was to verify the influence of recreational activities in the learning development and the global praxis of children registered in early childhood education. The sample was composed by 40 individuals registered in the 4 schools of public and private sectors, being 10 each school. For avaliation of global praxis were applied in the children the tests of battery of psychomotor of Vitor da Fonseca (1975) specific for that factor. For determination of ludicity of schools and the level of learning of children were used questionnaires, answered by the teachers, and adapted of the psychomotor battery. The data were treated in the descriptive and inferential form, and the results showed homogeneity between schools as regards the ludicity offered and the development of global praxis of their children. As for the learning, in the school more ludic the children showed better results, however without statistical support. Concluded is
\end{abstract}


necessary to investigate a larger number of schools in order to find more significant differences in reference of the ludicity, and thus able can to record most salient differences in global praxis and learning.

Keywords: Physical Education, Playfulness, Learning

\section{INTRODUÇÃO}

Para os educadores dos dias atuais está cada vez mais difícil manter o foco de atenção dos educandos, pois na escola, as crianças permanecem sentadas em suas carteiras durante horas, o que conflita com a necessidade latente de movimento característica dessa faixa etária. Com isso, e com o passar dos anos, elas começam a ter resistência em ir para a escola (ASSIS, 2010).

Como alternativa a esse processo, as atividades lúdicas funcionam como exercícios necessários e úteis, sendo as brincadeiras e jogos elementos indispensáveis para que haja uma aprendizagem com divertimento, que proporcione o prazer no ato de aprender, e que facilite as práticas pedagógicas em sala de aula (SALOMÂO e MARTINI, 2007). Isso parece lógico, pois, ao se associar a necessidade latente de movimento presente nas crianças com as demandas do processo de aprendizagem cria-se um cenário perfeito para a aprendizagem de novos conteúdos e/ou consolidação de conteúdos já aprendidos.

Nesse sentido Campos (2005) afirma que o jogo, nas suas diversas formas, auxilia no processo ensino-aprendizagem e no desenvolvimento psicomotor, isto é, no desenvolvimento da motricidade fina e ampla, bem como no desenvolvimento de habilidades do pensamento, como a imaginação, a interpretação, a tomada de decisão, a criatividade, o levantamento de hipóteses, a obtenção e organização de dados. Além da aplicação dos fatos e dos princípios a novas situações que, por sua vez, acontecem quando jogamos, quando obedecemos a regras, quando vivenciamos conflitos numa competição.

Diferindo do jogo, o brinquedo supõe uma relação intima com a criança e uma indeterminação quanto ao uso, ou seja, a ausência de um sistema de regras que organizam sua utilização (KISHIMOTO, 1994), o que leva a crer que o jogo orientado favorece mais o processo de ensino aprendizagem do que o brinquedo muitas vezes utilizado como ferramenta de mera distração para as crianças. Todavia, Mauricio (2008) defende que a brincadeira é um recurso que uma criança usa para se divertir de forma natural, ela usa a sua imaginação vivenciando o que ela quiser, da forma que quiser, sem se preocupar em seguir regras e planejamentos. É a principal atividade da criança quando não está dedicada às suas necessidades de sobrevivência, como dormir, se alimentar, etc. (MACEDO, PETTY e PASSOS, 2005).

A brincadeira não deve ser considerada então como uma simples atividade de distração para uma criança, pois ela tem um grande papel na vida de uma pessoa, para Maluf (2003) ela ajuda a criança a se desenvolver, promove a socialização e a descoberta de tudo que está a sua volta. Porém, parece claro que no contexto escolar as atividades lúdicas orientadas (jogos) são mais eficientes quando se almeja a otimização do processo de aprendizagem.

Então, como dito, a brincadeira ao acaso tem a sua importância, contudo Quintão et al (2004), afirmam que a interferência intencional do professor é fundamental para o desenvolvimento, pois deverá estimular o aluno a progredir em seus conhecimentos e habilidades através de propostas desafiadoras que o leve a buscar soluções, por intermédio da sua própria vivência. Isso evidencia a grande importância da presença do profissional licenciado em educação física nas séries da educação infantil. 
De acordo com Bezerra (2007), o papel do professor de educação física escolar, é de manter e intensificar o que ele já aprendeu e estimular o desenvolvimento de um novo ciclo. O profissional de Educação Física ao trabalhar em escolas deve saber as fases do desenvolvimento infantil, para saber quais os estímulos apropriados para aquela fase, pois assim, ele estará fazendo com que o desenvolvimento seja mais harmonioso no campo motor, cognitivo e afetivo-social (QUINTÃO et al, 2004).

Segundo Pinho (2009), a escola precisa se dar conta que através do lúdico as crianças têm chances de crescerem e se adaptarem ao mundo coletivo. O lúdico deve ser considerado como parte integrante da vida do homem não só no aspecto de divertimento, mas também no aspecto de adquirir conhecimento. Nesse sentido Teixeira (1995) diz que o ser que brinca e joga é, também, o ser que age, sente, pensa, aprende e se desenvolve.

Assim o objetivo desse trabalho é investigar se a oferta de atividades lúdicas na escola pode servir como agente potencializador da aprendizagem e do desenvolvimento da praxia global de seus alunos.

\section{MATERIAIS E MÉTODOS}

A amostra da pesquisa foi formada por 4 escolas do ensino fundamental situadas do interior no estado do Rio de Janeiro, onde foram escolhidas em cada escola de forma aleatória, 10 crianças de ambos os gêneros, para serem submetidas a testes que visam avaliar o nível de aprendizagem e o desenvolvimento psicomotor geral. Como critério de inclusão os 40 indivíduos deveriam estar regularmente matriculados na educação infantil, possuir de 4 a 6 anos, e não ter qualquer tipo déficit mental ou motor.

Os instrumentos selecionados para operacionalização do referido estudo são questionários desenvolvidos inspirados na bateria psicomotora de Vitor da Fonseca (1975) (Anexos 1 e 2) e a própria bateria, onde serão aplicados os testes referentes ao fator psicomotor praxia global.

Os primeiros dados coletados dizem respeito às atividades lúdicas oferecidas nas escolas, essas informações foram obtidas através de um questionário desenvolvido pelos próprios pesquisadores a partir da bateria psicomotora de Vitor da Fonseca (1975), e respondido na própria escola, em uma sala apropriada, com dia e hora marcados previamente. Tal instrumento é composto por questões que visam avaliar o grau de ludicidade oferecida pelas escolas aos alunos, sendo o mesmo ser respondido por professores e/ou pela coordenação da escola.

Estando determinados através do referido questionário os índices de ludicidade de cada escola, o próximo passo foi a determinação do nível de aprendizado e desenvolvimento psicomotor geral das crianças dessas mesmas escolas. Para a primeira avaliação proposta foi necessário uma nova adaptação da bateria psicomotora, sendo dessa vez direcionada para a avaliação do desenvolvimento da aprendizagem de crianças integradas à educação infantil. Já para a determinação do desenvolvimento psicomotor geral utilizar-se-á a própria bateria psicomotora de Vítor da Fonseca, instrumento altamente utilizado e validado para avaliações desse tipo (FONSECA, 1975).

Todos os procedimentos adotados estavam de acordo com a lei 196/96, sendo a pesquisa analisada e aprovada pelo comitê de ética dos Institutos Superiores de Ensino do Censa.

Em dia e hora marcados se procedeu a aplicação dos questionários de avaliação da ludicidade das escolas e de avalição do aprendizado das crianças matriculadas nessas mesmas escolas. Esses dois instrumentos foram respondidos pelos próprios professores que, além de estar inteirados das práticas lúdicas oferecidas na escola também são os mais aptos a descrever o nível de aprendizado de cada criança que posteriormente seriam submetidas aos testes da bateria psicomotora.

No dia seguinte a coletas dos dados iniciais sobre a oferta de atividades lúdicas pelas escolas e a aprendizagem de 10 crianças de cada escola escolhidas aleatoriamente. Essas mesmas crianças foram 
submetidas às atividades da bateria psicomotora de Vitor da Fonseca (1975) que objetivam avaliar o fator praxia global. Estes testes foram feitos de forma individual em salas reservadas com estímulos externos controlados e espaço suficiente para a execução das tarefas, que foram cedidas pelas próprias escolas.

Os dados provenientes do estudo foram analisados descritiva e inferencialmente. Para análise descritiva foram escolhidos a média e a mediana como valores de tendência central, o desvio padrão como medida dispersão além dos valores mínimo e máximo.

Já para análise inferencial foi utilizada a análise de variância onde para os dados paramétricos foi utilizado ANOVA (One Way), com teste de Tukey como teste complementar, e para os não paramétricos o Kruskal Wallis Test, sendo aplicado como teste complementar o método de comparação de Dunn.

\section{RESULTADOS E DISCUSSÃO}

Inicialmente os escores dos testes foram analisados de forma descritiva através de medidas de tendência central, extremos e dispersão. A referida analise encontra-se ilustrada na tabela 1.

Tabela 1 - Descrição dos dados referentes a média, mediana, escores mínimo e máximo, e desvio padrão dos testes de aprendizado e praxia global dos indivíduos da pesquisa, além do escore de ludicidade obtido pelas escolas envolvidas no estudo.

\begin{tabular}{|c|c|c|c|c|c|c|c|}
\hline & $\begin{array}{l}\text { Escore de } \\
\text { Ludicidade }\end{array}$ & $\begin{array}{c}\text { Testes } \\
\text { Aplicados } \\
\end{array}$ & Média & Mediana & Mínimo & Máximo & $\begin{array}{l}\text { Desvio } \\
\text { Padrão }\end{array}$ \\
\hline \multirow{2}{*}{ Escola 1} & \multirow{2}{*}{12} & $\begin{array}{l}\text { Praxia } \\
\text { Global }\end{array}$ & 4,2 & 4 & 2 & 6 & 1,5 \\
\hline & & $\begin{array}{c}\text { Teste do } \\
\text { Aprendizado }\end{array}$ & 22,0 & 21 & 20 & 26 & 2,5 \\
\hline \multirow{2}{*}{ Escola 2} & \multirow{2}{*}{12} & $\begin{array}{l}\text { Praxia } \\
\text { Global }\end{array}$ & 5,6 & 6 & 5 & 7 & 0,7 \\
\hline & & $\begin{array}{c}\text { Teste do } \\
\text { Aprendizado }\end{array}$ & 19,1 & 19 & 16 & 24 & 2,2 \\
\hline \multirow{2}{*}{ Escola 3} & \multirow{2}{*}{14} & $\begin{array}{l}\text { Praxia } \\
\text { Global }\end{array}$ & 4,4 & 4 & 3 & 7 & 1,7 \\
\hline & & $\begin{array}{c}\text { Teste do } \\
\text { Aprendizado }\end{array}$ & 22,5 & 23 & 20 & 24 & 1,4 \\
\hline \multirow{2}{*}{ Escola 4} & \multirow{2}{*}{12} & $\begin{array}{l}\text { Praxia } \\
\text { Global }\end{array}$ & 4,5 & 5 & 2 & 6 & 1,2 \\
\hline & & $\begin{array}{c}\text { Teste do } \\
\text { Aprendizado }\end{array}$ & 18,1 & 16 & 14 & 34 & 6,2 \\
\hline
\end{tabular}

A tabela 1 permite através de uma análise descritiva levantar algumas ideias preliminares. Nesse sentido, com respeito ao índice que visa mensurar a oferta de atividades lúdicas, a maioria das escolas se mostraram homogêneas. Com exceção da escola 3 que registrou 14 pontos nessa avaliação, sendo a escola que, segundo os parâmetros estabelecidos, oferece maior ludicidade aos seus alunos. Todavia o objetivo do estudo é saber se essa maior oferta influência no desenvolvimento da praxia global e do aprendizado, e para isso se faz necessário a análise das outras variáveis mensuradas.

O teste de praxia global mostrou que na escola 2 e 4 as crianças apresentaram, respectivamente, os melhores desempenhos. Nas escolas 1 e 3 elas obtiveram um desempenho inferior, contudo, bem próximo ao das escolas 2 e 4 . Tal proximidade nos resultados parece compatível com a homogeneidade encontrada na oferta de atividades lúdicas as crianças não só na escola mas também no contexto social no qual as mesmas estão inseridas. 
Com relação à variável aprendizado, houve uma maior variação nos resultados. Nesse teste as crianças da escola 3 alcançaram pontuação mais elevada, seguidas pelas crianças das escolas 1,2 e 4 respectivamente. Essa variável aponta que, com relação ao aprendizado, na escola mais lúdica as crianças se mostraram mais desenvolvidas. Corroborando com essa conclusão Santana (2006) evidencia que, devido à atuação das atividades prazerosas no organismo, as atividades lúdicas facilitariam a aprendizagem por sua própria acepção, pois os mecanismos para os processos de descoberta são intensificados.

A figura 1 ilustra as observações feitas até aqui.

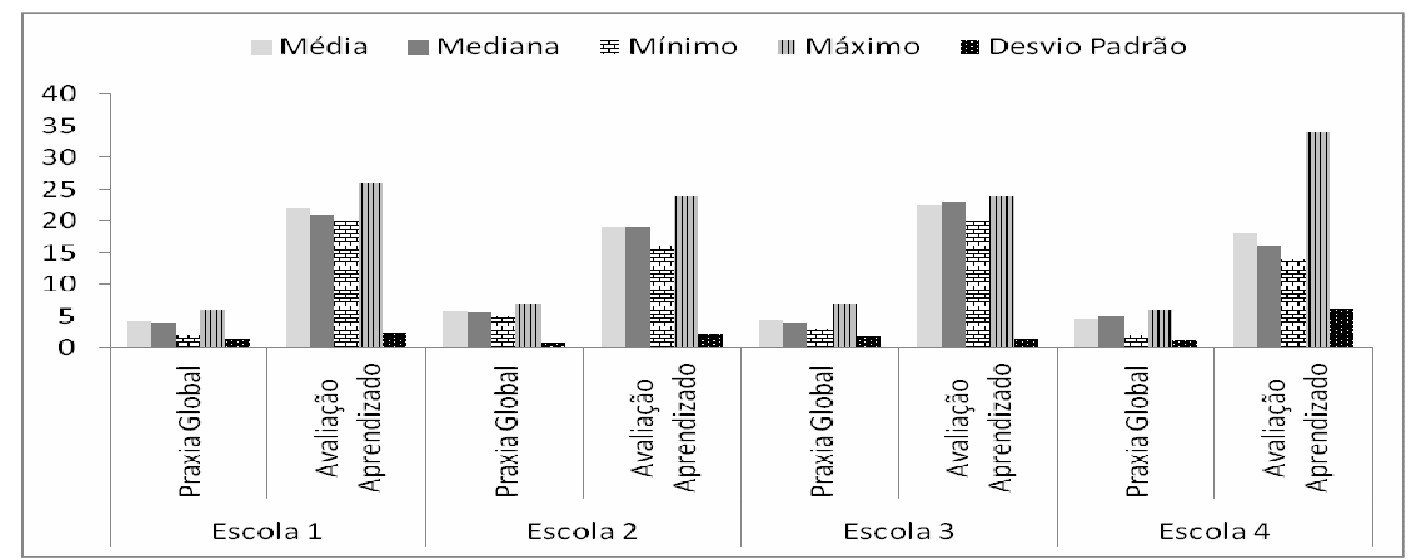

Figura 1 - Dados descritivos obtidos através dos testes de Praxia Global e Aprendizado.

Para que se possam confirmar as observações feitas através da análise descritiva dos dados se faz necessário uma análise inferencial dos mesmos, objetivando a verificação se as diferenças já expostas possuem alguma relevância estatística.

Dessa forma, buscando atender essa necessidade, aplicaram-se dois testes de análise de variância. Devido a sua natureza paramétrica, os dados do teste de praxia global foram analisados através da ANOVA (One Way), por outro lado, os escores do teste de aprendizado por apresentarem características nãoparamétricas forma analisados pelo Kruskal Wallis Test, adotando-se como teste complementar o método de Dunn. Os resultados dessas análises estão descritos nas tabelas 2 e 3.

Tabela 2 - Teste de analise de variância ANOVA (One Way) dos dados referentes do teste de praxia global aplicados nas crianças das 4 escolas participantes do estudo.

\begin{tabular}{|c|c|c|c|c|}
\hline FONTES DE VARIAÇÃO & GL & & SQ & QM \\
\hline Tratamentos & & 3 & 9.669 & 3.223 \\
\hline Erro & & 26 & 42.631 & 1.640 \\
\hline $\mathrm{F}=$ & 1.9658 & & & \\
\hline$(p)=$ & 0.1429 & & & \\
\hline
\end{tabular}

A tabela 2 deixa claro que com relação ao desenvolvimento da praxia global todas as escolas estavam estatisticamente iguais, corroborando com os escores de ludicidade que também expressaram homogeneidade entre as escolas. Como já dito, possivelmente essa igualdade estatística se dá pelo fato de que todas as escolas envolvidas nessa pesquisa relataram que seus alunos "NUNCA" realizam atividades lúdicas orientadas por professores de educação, então presume-se que a desenvolvimento da praxia global registrado se dá apenas pelas brincadeiras e estímulos que as crianças recebem em seu meio social. 
Tabela 3 - Análise de variância não-paramétrica dos dados do teste de aprendizado, através do teste de Kruskal Wallis com múltiplas comparações feitas pelo método de Dunn.

\begin{tabular}{|c|c|c|c|c|}
\hline & Resultados & & & \\
\hline $\mathrm{H}=$ & 16.2279 & & & \\
\hline Graus de liberdade $=$ & 3 & & & \\
\hline (p) Kruskal-Wallis $=$ & $0.0010^{*}$ & & & \\
\hline $\mathrm{R} 1=$ & 263.5000 & & & \\
\hline $\mathrm{R} 2=$ & 156.0000 & & & \\
\hline $\mathrm{R} 3=$ & 289.5000 & & & \\
\hline $\mathrm{R} 4=$ & 111.0000 & & & \\
\hline $\mathrm{R} 1$ (posto médio) $=$ & 26.3500 & & & \\
\hline $\mathrm{R} 2$ (posto médio) $=$ & 15.6000 & & & \\
\hline R 3 (posto médio) $=$ & 28.9500 & & & \\
\hline $\mathrm{R} 4$ (posto médio) $=$ & 11.1000 & & & \\
\hline Comparações (método de Dunn) & Dif. Postos & $\mathrm{z}$ calculado & $\mathrm{z}$ crítico & $\mathrm{p}$ \\
\hline Entre as Escolas 1 e 2 & 10.7500 & 2.0562 & 2.635 & ns \\
\hline Entre as Escolas 1 e 3 & 2.6000 & 0.4973 & 2.635 & ns \\
\hline Entre as Escolas 1 e 4 & 15.2500 & 2.9169 & 2.635 & $<0.05^{*}$ \\
\hline Entre as Escolas 2 e 3 & 13.3500 & 2.5535 & 2.635 & ns \\
\hline Entre as Escolas 2 e 4 & 4.5000 & 0.8607 & 2.635 & ns \\
\hline Entre as Escolas 3 e 4 & 17.8500 & 3.4142 & 2.635 & $<0.05^{*}$ \\
\hline
\end{tabular}

$* \mathrm{p}<0,05 ; \mathrm{ns}=$ não significativa

A tabela 3 deixa claro através do índice $p=0,001$, que existiram diferenças estatisticamente significativas entre as escolas. O método de comparação de Dunn apontou que a significância estatística se encontrava entre as escolas 1 e 4, e, 3 e 4 . As escolas 3 e 1 alcançaram a primeira e segunda melhores pontuação no teste de aprendizado, mas foram estatisticamente superiores apenas a escola 4 que recebeu a menor pontuação, porém essa diferença estatística não existiu quando a variável observada foi a praxia global.

Com relação a ludicidade a escola 3 se destacou com 14 pontos, e todas as outras tiveram apenas 12 , ou seja, mesmo com índices de ludicidade iguais houve diferenças significativas entre elas no que diz respeito a aprendizagem. Assim, não é possível, somente com esses dados, se comprovar de forma definitiva que o fator ludicidade influenciou significativamente na aprendizagem dessas crianças. Todavia, não se pode menosprezar as conclusões oriundas da análise descritiva, essa apontou de forma conclusiva que na escola com maior oferta de atividades lúdicas estavam as crianças com maior desenvolvimento da aprendizagem. Possivelmente outras variáveis como a didática e o método de ensino, adotados por cada escola, tenham tido alguma influência sobre o resultado desse teste.

Já a igualdade registrada no teste de praxia global pode se justificar pelas próprias características da cidade onde se desenvolveu o estudo, onde ainda prevalecem características de cidade do interior, com grande oferta de espaços favoráveis ao desenvolvimento dessas práxis por meio dos próprios jogos e brincadeiras próprios da faixa etária avaliada, e pela ausência professores de educação física nas escolas estudadas, o que de certa forma limita o desenvolvimento psicomotor das crianças no ambiente escolar as "brincadeiras ao acaso". A esse respeito Rosa Neto (1996), diz que o conceito de praxia global "é a ação psicomotora representada pelos movimentos dinâmicos globais (correr, saltar, trepar, andar, etc.)", que de certa forma podem ser desenvolvidos por brincadeiras "ao acaso" praticadas no meio social em que elas estejam inseridas. Esta visão se respalda no conceito de Mello (1996), que afirma que a praxia global como "a harmonia dos movimentos voluntários dos grandes segmentos do corpo ou a capacidade de controle dos 
atos motores que põe em ação todo o corpo". Porém Bezerra (2007) e Quintão et al (2004) defendem a importância da intervenção do professor de educação física como agente direcionador e potencializador desse desenvolvimento, o que não existia em nenhuma das escolas estudadas.

\section{CONCLUSÃO}

Pode-se concluir através dos dados levantados nessa pesquisa que os objetivos foram parcialmente atingidos uma vez que a análise descritiva comprovou que na escola onde as crianças tinham mais ofertas de atividades lúdicas foram registrados maiores índices de aprendizado.

Com relação à variável praxia global, registrou-se uma homogeneidade nas escolas avaliadas possivelmente devido a inexistência de professores de educação física nessas escolas que pudessem direcionar o desenvolvimento dessa variável.

Devido à grande relevância do tema abordado sugere-se que outros estudos, que busquem comparar um número maior de escolas e indivíduos, sejam conduzidos a fim de que se possa caracterizar de forma conclusiva a influência das atividades lúdicas no desenvolvimento da aprendizagem.

\section{REFERENCIAS}

ASSIS, Rosimar Moreira. Brincando e Aprendendo: O Papel do lúdico no ensino / Aprendizagem em diferentes contextos sociais. Monografia apresentada na graduação do curso de pedagogia do Centro de Educação Superior a Distância do Estado do rio de Janeiro - CEDERJ. 2010.

BEZERRA, Edson Alves. Porque Trabalhar O Lúdico Na Educação Infantil. Webartigos, 2007.

Disponível em: http://www.webartigos.com/articles/2985/1/Porque-Trabalhar-O-Ludico-Na-EducacaoInfantil/pagina1.html. Acesso em: 3 de junho de 2011.

CAMPOS, Maria Célia Rabello Malta. A importância do jogo no processo de aprendizagem. Revista Psicopedagogia Online, 2005. $\quad$ Disponível em: http://www.psicopedagogia.com.br/entrevistas/entrevista.asp?entrID=39. Acesso: 26 de Abril de 2011.

FONSECA, V. Manual de observação psicomotora: Significação psiconeurológica dos fatores psicomotores. Porto Alegre: Artes Médicas. 1995.

KISHIMOTO, T.M. Jogo, Brinquedo, Brincadeira e a Educação. 6. ed. São Paulo: CORTEZ, 1994.

MACEDO, Lino; PETTY, Ana Lúcia Sícoli; PASSOS, Norimar Christe. Os jogos e o lúdico na aprendizagem escolar. Edições Artmed. Porto Alegre, 2005.

MALUF, Ângela Cristina Munhoz. A importância das brincadeiras na evolução dos processos de desenvolvimento humano. Revista Psicopedagogia Online, 2003. Disponível em: http://www.psicopedagogia.com.br/opiniao/opiniao.asp?entrID=132.

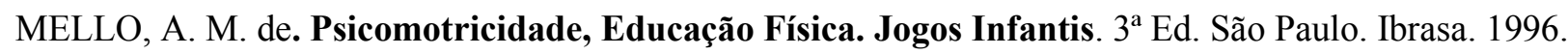

PINHO, Raquel. O lúdico no processo de aprendizagem. Webartigos, 2009. Disponível em: http://www.webartigos.com/articles/21258/1/O-LUDICO-NO-PROCESSO-DE-

APRENDIZAGEM/pagina1.html . Acesso em: 26 de Maio de 2011.

QUINTÃO, Dalila; PINHEIRO, Elisa; PASSOS, Felipe; Santos, Larissa; XAVIER, Márcia; NUNES, Márjorie. Centro de Ciências de Educação e Humanidades - CCEH - Universidade Católica de Brasília UCB - Volume 1 - Número 2. 2004. 
ROSA NETO, F. Valoracion del desarrollo motor y su correlacion com los transtornos del aprendizage. Tesis doctoral. (Faculdade de Medicina - Departamento de Fisiatria y Enfermeria) Universidad de Zaragoza, Zaragoza, 1996.

SANTANA, Eliana Moraes de. A Influência de atividades lúdicas na aprendizagem de conceitos químicos. Universidade de São Paulo, Instituto de Física - Programa de Pós-Graduação Interunidades em Ensino de Ciências - 2006.

TEIXEIRA, C.E.J. A Ludicidade na Escola. São Paulo: LOYOLA, 1995. 